\title{
Francisco García Fitz y Feliciano Novoa Portela, Cruzados en la Reconquista. Marcial Pons Historia, Madrid, 2014, 143 PÁGinas. Prólogo de Miguel Ángel Ladero Quesada. ISBN: 9788415963226
}

EnRiQue RodrígueZ-PICAVEA Universidad Autónoma de Madrid

Las investigaciones sobre las cruzadas y la Reconquista se han desarrollado de manera notable en las últimas décadas, dando lugar a un importante número de aportaciones historiográficas, que han venido a enriquecer notablemente nuestro conocimiento sobre el tema. En el contexto de estas aportaciones hacía falta la aparición de una visión de conjunto, con vocación de síntesis, sobre la participación de los cruzados europeos en la Reconquista. Esto es precisamente lo que nos ofrecen en esta obra Francisco García Fitz y Feliciano Novoa Portela, dos medievalistas de dilatada trayectoria.

En primer lugar, resulta obligado destacar que el libro que comentamos es la primera monografía sobre el tema que desarrolla. Para llevar a buen término su estudio los autores se apoyan en un importante abanico de fuentes cronísticas y documentales. El libro aparece dividido en seis capítulos. Dos de ellos, el primero y el último, de corte más conceptual, mientras que los cuatro centrales tienen un planteamiento claramente diacrónico.

En el primer capítulo se analizan los conceptos de Cruzada y Reconquista, dos de los temas más debatidos por la historiografía. Se hace un estado de la cuestión de ambos conceptos, que resulta imprescindible pórtico de entrada a los asuntos que posteriormente van a ser tratados en el resto del libro. El análisis del debate historiográfico sobre la Cruzada permite a los dos autores llegar a dos conclusiones. La primera es que es difícil llegar a una definición «inequívoca y lúcida» del fenómeno, tal y como pedía Mayer. La segunda es que la Cruzada es la consecuencia más llamativa del reformismo gregoriano. Por otra parte, después de la revisión historiográfica de la Reconquista, los autores la consideran una creación ideológica de las minorías cultas mozárabes durante los siglos IX y X, aunque piensan que el ideario reconquistador probablemente esté ya presente en las obras de Beato de Liébana, de finales del siglo VIII.

A continuación, Francisco García Fitz y Feliciano Novoa Portela exploran las relaciones existentes entre Cruzada y Reconquista. Una de las diferencias entre ambos conceptos 
es que la primera constituye una empresa de salvación individual, encabezada por los papas y destinada a conseguir un objetivo universal para toda la cristiandad, mientras que la segunda persigue una salvación colectiva, liderada por los monarcas ibéricos y con el objetivo común de recuperar lo que los antepasados habían perdido. Una segunda diferencia estriba en la diferente percepción de la dinámica histórica, de la guerra en las fronteras hispánicas y del «Otro» que tenían los cruzados europeos y el papado frente a la que tenían los reyes y la sociedad peninsular. Sin embargo, y pese a las discrepancias, no eran pocos los puntos de conexión entre la ideología cruzadista universal y la reconquistadora hispánica. Desde los argumentos jurídicos, que aludían a la recuperación de un bien perdido, hasta los religiosos, que recordaban la sacralidad del combate contra los infieles. Estas coincidencias facilitaron la superposición temporal o circunstancial de Cruzada y Reconquista en el marco de una misma campaña o contexto.

El segundo capítulo se centra en el período anterior a la Primera Cruzada, concretamente analiza la participación de los guerreros europeos en la temprana Reconquista hispánica. Se divide en dos partes. La primera incluye hasta la toma de Barbastro (1064), que por su importancia es el acontecimiento al que dedican mayor espacio. La segunda parte estudia las intervenciones de combatientes europeos en tierras ibéricas hasta la predicación de la Cruzada por el papa Urbano II.

A continuación, los autores dedican dos capítulos al período cronológico que consideran más importante y significativo en la llegada de cruzados a la Reconquista: 1096-1217. Los dos capítulos responden a las dos tipologías de intervenciones cruzadas que establecen. La primera es la de los cruzados que venían a un frente específico, que era el de la Península ibérica. Una modalidad que es más antigua y que tuvo también una mayor continuidad. La segunda tipología es la de aquellos cruzados que acuden a un frente circunstancial, ya que están de paso hacia Tierra Santa y ese es su verdadero objetivo de combate. Sea como fuere, entre 1096 y 1217 se producen las más importantes intervenciones de guerreros europeos en la Reconquista, tanto desde el punto de vista cuantitativo como cualitativo. Las tropas exteriores fueron decisivas durante esos años para las conquistas de Zaragoza, Tortosa, Lisboa, Silves o Alcaçer do Sal. Todo ello fue posible porque se había desarrollado un adecuado caldo de cultivo: la Península ibérica, a los ojos de los pontífices romanos, se había convertido en un frente cruzado. El conflicto ibérico fue equiparado con la peregrinación a Tierra Santa y las cruzadas hispánicas fueron bendecidas por los papas.

Sin embargo, a partir de 1217 y hasta 1492, el peso específico y la visibilidad de los cruzados es menor, más testimonial que efectivo. A analizar este período se dedica el capítulo quinto del libro. La disminución de la presencia está relacionada con dos cuestiones. En primer lugar el fortalecimiento de las monarquías ibéricas y, en segundo lugar, la atenuación del espíritu cruzadista, especialmente patente desde la pérdida de los territorios del Oriente latino a finales del siglo XIII. Algún episodio, como el asedio de Algeciras, todavía suscita el entusiasmo de los cruzados europeos, pero lo habitual fue la llegada de pequeños grupos o de caballeros a título individual, que quizás venían a la frontera granadina movidos más por el espíritu caballeresco que por la religiosidad militar. 
Por fin, el sexto capítulo se dedica a estudiar la imagen de los cruzados en los reinos ibéricos medievales. En este sentido, desde fechas tempranas, se observa la existencia de testimonios hispánicos en los que se forman unos estereotipos con una fuerte carga negativa o despectiva. Así se muestra de ellos su faceta más denigrante: la crueldad, la cobardía, la indisciplina, la ineficacia o la estupidez. En el mejor de los casos su presencia es ignorada u oscurecida. Se les considera extraños, diferentes, distintos. Por eso, como escribió un autor toledano, eran «gientes que non entendíamos».

En definitiva, la monografía de Francisco García Fitz y Feliciano Novoa Portela cumple plenamente con las expectativas iniciales. Escrita de una manera clara y directa, se ha convertido desde el día de su publicación en una referencia inexcusable y una magnífica síntesis sobre la participación de los guerreros europeos en la Reconquista, gracias a una utilización inteligente de las fuentes documentales y de la bibliografía especializada. 
